\title{
Vikingland e a epopeia da emigración
}

\author{
Vikingland and the Epic of Emigration
}

\author{
José Antonio Cascudo \\ xacascudo@gmail.com \\ [recibido 30/10/2014, aceptado 05/02/2015]
}

\section{RESUMO}

$\mathrm{O}$ artigo versa sobre a construción da identidade cultural galega desde o audiovisual, tomando como punto de referencia Vikingland (2011) de Xurxo Chirro. O propósito é explorar os lugares comúns do fenómeno migratorio comparando este filme con obras afíns como Mamasunción (1984) ou Avión, el pueblo ausente (2011), co obxectivo de conformar un depósito visual da nosa memoria colectiva.

PALABRAS CHaVE: Emigración, cinema, Galicia, Xurxo Chirro, Vikingland.

\section{RESUMEN}

El artículo versa sobre la construcción de la identidad cultural gallega desde lo audiovisual, tomando como punto de referencia Vikingland (2011) de Xurxo Chirro. El propósito es explorar los lugares comunes del fenómeno migratorio comparando este filme con obras afines como Mamasunción (1984) o Avión, el pueblo ausente (2011), con el objetivo de conformar un depósito visual de nuestra memoria colectiva.

PALABRAS Clave: Emigración, cine, Galicia, Xurxo Chirro, Vikingland.

\begin{abstract}
This article focuses on the construction of cultural identity through Galician audiovisual production, taking the film Vikingland (2011) by Xurxo Chirro as a reference. The purpose of this study is to explore the leitmotifs of the migratory phenomenon by comparing this production with other related works such as Mamasunción or Avión, el pueblo ausente in order to build a visual repository of Galician collective memory.
\end{abstract}

KEY WORDS: Emigration, cinema, Galicia, Xurxo Chirro, Vikingland.

CAscudo, J. A. (2015): “Vikingland e a epopeia da emigración”, Madrygal (Madr.), 18, Núm. Especial: 541-546.

SUMARIO: 1. A imaxe e a ausencia. 2. A epopeia da emigración. 3. A emigración no audiovisual galego: de $M a-$ masunción a Avión, el pueblo ausente. 4. Vikingland, a emigración desde dentro. 5. Conclusións. 6. Referencias bibliográficas. 


\section{A IMAXE E A AUSENCIA}

En El objeto del siglo Gerard Wajcman remexe no que el mesmo denomina o "Gran Bazar" moderno na procura de cousas que lle axuden a definir o século XX. Tras unha longa reflexión conclúe que son dous os artefactos alí almacenados, A roda de bicicleta de Duchamp (1913) e o Cadrado negro sobre fondo branco de Málevich (1913), os merecentes desta distinción (Wajcman 2001: 25).

Que teñen en común estas dúas obras? Segundo Wajcman ambas as dúas atópanse embebidas da doutrina ética e estética do baleiro. A obra de arte non é a que dá a ver o invisible, senón a que "fai ver" aquilo que non hai. Neses dous obxectos prodúcese un salto do baleiro á ausencia; é dicir, "pintar a ausencia convértese no proxecto deliberado do artista" (Wajcman 2001: 92).

Abondando sobre o particular, Wajcman engade outra interesante hipótese sobre o noso pasado inmediato: o século XX érguese sobre unha ausencia encarnada nas ruínas, pero non tanto nas ruínas físicas -refírese, sobre todo, aos vestixios dos conflitos bélicos- coma noutro tipo de ruínas, aquelas que os nosos ollos son incapaces de percibir, pero que implosionan na conciencia (2001: 190). Os "monumentos invisibles" de Jochen Gerz ou Shoah (1985), o filme documental de Claude Lanzmann sobre os campos de exterminio, son paradigmas desta sorte de "imaxe da ausencia", que Wajcman, seguindo a Freud, califica de "ciencia do esquecemento" (2001: 18).

Salvando as connotacións bélicas, esta suxestiva tese da imaxe como ausencia podería explicar o noso particular contexto sociocultural. A imaxe da Galicia contemporánea edifícase tamén sobre a ausencia, a ausencia dos que marcharon á procura dun futuro mellor. E é esta ruína, invisible e silenciosa, de cada familia, a que cómpre salvagardar para que permaneza como obxecto de memoria.
A emigración constitúe un dos feitos capitais da Galicia contemporánea, onde baleiro e ausencia se retroalimentan. Realizar unha análise global do fenómeno migratorio permitiranos reconstruír con maior fidelidade os nosos principios identitarios como pobo.

\section{A EPOPEIA DA EMIGRACIÓN}

Non resulta doado cuantificar o número de galegos que marcharon á procura de fortuna desde mediados do século XIX. Do que non hai dúbida é de que se tratou dunha mobilización masiva orixinada nas zonas rurais para fuxir da miseria provocada pola superpoboación e a escaseza de recursos ${ }^{1}$. A historiografía destaca dúas vagas principais, a primeira a América desde mediados do século XIX até o primeiro terzo do XX, e outra ao norte e centro de Europa nas décadas dos sesenta e setenta do século pasado (Bertrand 2000: 440-446).

Dentro dos fluxos migratorios existen dous tipos: o permanente e o estacional. No caso de emigración permanente, sobre todo no caso do éxodo a América, unha das súas peculiaridades era a dificultade do regreso, debido á precariade das comunicacións transoceánicas. No caso da emigración a Europa o carácter estacional foi porcentualmente superior, pola menor distancia e a tipoloxía de emigrante, que segundo Bertrand (2000: 448) era de idade superior, preferentemente cabezas de familia maiores de 35 anos, o cal supoñía unha garantía de retorno. Na emigración estacional xogan un papel fundamental os mariñeiros que se dirixen a determinadas zonas para faenar ou para realizar traballos de temporada, como no caso que nos ocupa, o de Vikingland, nun transbordador.

A análise do fenómeno migratorio deu a prelo un inxente número de volumes históricos, sociolóxicos e demográficos; e como non podía ser doutro xeito foi tema recorrente en numerosas obras literarias. O que nos ocupa

\footnotetext{
${ }^{1}$ Non é a intención deste artigo fornecer datos senón de constatar as convulsións demográficas producidas pola emigración. Sirva a modo de exemplo o estudo de Vázquez González (s. d.), que cifra en 1450000 as saídas de galegos a América entre 1886 e 1936.
} 
neste artigo é o modo en que a emigración e as súas consecuencias foron reflictidas no audiovisual. O número de obras que atinxen este tema resulta moi inferior a outras disciplinas debido a que este sector foi e continúa a ser unha industria en precario.

\section{A EMIGRACIÓN NO AUDIOVISUAL GALEGO: DE MAMASUNCIÓN A AVIÓN, EL PUEBLO AUSENTE}

Mamasunción (Chano Piñeiro, 1984) é un dos filmes fundacionais do cinema galego; unha curtametraxe que contou cunha axuda da nacente política audiovisual da Xunta de Galicia $^{2}$, realizada sen grandes recursos materiais pero con enormes doses de enxeño e talento, capaces de conmover espectadores de medio mundo ${ }^{3}$.

Mamasunción aborda desde a ficción o tema da emigración a América. Unha anciá que vive nunha remota aldea do interior de Galicia agarda a carta dun fillo emigrado en México. Un día por fin chega a misiva, pero trae noticias nefastas: o fillo morreu e o contido desas liñas son a herdanza que compartirá a vella co concello. Acto seguido a muller marcha camiño da casa e alí queima os billetes recibidos.

Parece ser que Piñeiro se baseou nunha fotografía de Manuel Ferrol que retrata unha muller de Buño da que dicían que se volvera tola agardando por un mozo que marchara a América. Tampouco é moi relevante saber se o guión está inspirado nun feito real ou non pois o esencial é que o relato resulte verosímil, e esa verosimilitude é a que causa un impacto emocional no espectador. As imaxes de Mamasunción enténdense en calquera lugar porque todos os pobos achegaron ou recibiron emigrantes nalgún momento da súa historia. En último termo o que define o relato é o seu carácter profundamente humano, condesado no xesto de queimar os cartos, un acto de suprema irreverencia, de vinganza ante o destino.

O rostro sucado de engurras de Sunción Ogando constitúe o epítome de Galicia, simboliza a nai, o sufrimento da espera e a abnegación. E xunto con outros elementos (actores amateurs, paisaxe, fala popular) axudan a conformar a "verdade etnográfica" do filme. Mamasunción é unha "viúva de vivo" (neste caso nai), ao comezo do filme cando vagabundea agardando a carta do fillo, e será "viúva de morto" no desenlace.

Xustamente esa epígrafe "As viúvas de vivos e as viúvas dos mortos" coa que Rosalía de Castro titulou a quinta parte de Follas novas é unha imaxe que lle acae á protagonista do filme, e algúns dos seus versos son como a ladaíña existencial de Mamasunción:

Iste vaise e aquel vaise e todos, todos se van; Galicia sin homes quedas que te poidan traballar. Tés, en cambio, orfos e orfas, tés campos de soedade.

Tés mais que non teñen fillos, e fillos que non teñen pai. E tés corazóns que sofren longas ausencias mortais, viudas de vivos e mortos que ninguén consolará. (Castro 2004: 242)

Toda a curtametraxe semella impregnada da atmosfera asfixiante, do baleiro e da ausencia das fotografías de Manuel Ferrol, autor cuxo influxo se amosará de xeito máis patente en Sempre Xonxa (1989), o seguinte filme de Piñeiro, concretamente na secuencia da partida do barco. Unha iconografía similar da emigración atopámola na obra de Virxilio Viéitez (natural de Forcarei, como o cineasta), fotógrafo cuxas imaxes foron "encargadas para seren enviadas á familia que estaba en

${ }^{2}$ Unha fermosa carta dentro dunha lata, blog de Miguel Anxo Fernández (http://blogdemiguelanxofernandez.blogspot.com.es/2013/03/facendo-memoria-chano.html).

${ }^{3}$ Algúns dos festivais nos que participou Mamasunción foron: Bilbao, Oberhausen, Cracovia, Sydney, Melbourne, Clermont-Ferrand, Newcastle, Uppsala, Toldheim, Moscova, Gante ou Tetuán. 
América, adquirindo a fotografía un papel notarial" (Sendón 1998: 21), como é o caso da xa célebre muller que posa xunto á radio mercada cos cartos procedentes de ultramar.

Mamasunción, como moitas das mulleres que quedaron soas (nais, esposas e fillas), encarna o mito da eterna espera, como milleiros de Penélopes que agardaron infrutuosamente o regreso dos seus seres queridos; "representa la espera sin desaliento, la custodia de la casa y la vinculación con el origen que obligará finalmente a regresar de alguna manera al Odiseo ausente" (González 2012: 105). Unha idea que gravita sobre algúns dos versos de Xosé María Díaz Castro, desde a "longa rúa de mar" do poema Coma brasas á pregunta sen resposta de Penélope, "Traguerán os camiños algún día a xente que levaron".

Tamén sobre feridas sen cicatrizar se constrúe Avión, el pueblo ausente (María e Marcos Hervera, 2011), un documental no que a ausencia se presinte en cada plano. $\mathrm{O}$ contraste entre a "arquitectura das ruínas" dos que quedaron coa arquitectura ostentosa dos "mexicanos", os que marcharon e volveron millonarios. Pero tras esa opulencia intuímos os danos colaterais daqueles que deixaron a terra, o desarraigo (identidade difusa, ser forasteiros en todos os lugares); o exemplo máis evidente é o daquela muller que foi ao altar co sogro para oficiar un casamento mediante poder notarial do fillo, emigrado en América. Gran metáfora da ausencia.

Avión, el pueblo ausente combina imaxes actuais con arquivos familiares e entrevistas, vertebrando o relato arredor das estacións; o inverno no que só fican na vila os vellos, a primavera, que conta a historia dos primeiros emigrantes galegos; o verán, o tempo do reencontro cos emigrados, das verbenas, dos voos privados, de ocupar as mansións que o resto do ano permanecen deshabitadas, e o outono que marca o regreso a América dos "mexicanos".
Virxilio Viéitez utilizaba con frecuencia os haigas $^{4}$ como atrezzo, como elemento descontextualizado que enchía de crueza a imaxe das aldeas polas que se ganaba o sustento. Vendo os Ferraris, Porsches e Lamborghinis de Avión, el pueblo ausente podemos concluír que en realidade os efectos e consecuencias da emigración -enriquecemento, envilecemento, desarraigamento- seguen vixentes décadas despois.

\section{VIKINGLAND, A EMIGRACIÓN DES- DE DENTRO}

A mediados da década dos noventa un mariñeiro da Guarda chamado Luís Lomba, o Haia, merca unha cámara doméstica coa intención de reflectir a vida cotiá dos tripulantes do transbordador Vikingland durante unha travesía polo Mar do Norte, entre a cidade danesa de Romo e a illa alemá de Sylt.

Máis dunha década despois, Xurxo Chirro, fillo dun dos compañeiros do Haia, atopa na súa casa unha copia en VHS daquelas gravacións (con case dezaseis horas de metraxe). A fascinación que exerce sobre Chirro o descubrimento deste material anímao a iniciar o labor de edición das imaxes. O obxectivo final non era outro que revelar as duras condicións de vida dos emigrados galegos na diáspora, colectivo do que el tamén formara parte. Así xorde Vikingland (2011).

Xurxo Chirro opera no rexistro formal e conceptual do filme; súas son a "idea e manipulación", renunciando ao papel de director. Seguindo esta premisa traballa cun material atopado, rescatado, pero non o profana: "Yo no estoy de acuerdo cuando hablan de Vikingland en clave found-footage. El found-footage lo que hace es juntar A + B para contar una historia $\mathrm{C}$, y yo quería contar y potenciar la historia que ya estaba en el material" (Bergner, Rosal e Salles Kobilanski 2013). Como cineasta que é, e como mariñeiro que foi, Chirro vai dotando

\footnotetext{
${ }^{4} \mathrm{O}$ termo haiga xorde na posguerra cando se dicía que persoas enriquecidas de xeito abrupto, ben polo mercado negro ou polo estraperlo (ou tamén xente que facía fortuna na emigración), á hora de mercar un coche pedían "o máis grande que haiga".
} 
o relato de profundidade ontolóxica segundo transita por un territorio dramático que domina con solvencia.

Chirro aprópiase das imaxes do Haia e establece un diálogo coa historia do cinema coa intención de conferirlle entidade ao filme máis alá do mero discurso antropolóxico. Vikingland non só constitúe unha crónica documental senón que se mestura co xénero de aventuras, mesmo co Moby Dick (1851) de Melville. E, por riba de todo, privilexia un elemento capital, o humor, que acaba por converter esta obra nun monumento á retranca. Quizais por iso consegue algo inusual nun filme pretendidamente experimental: seducir o espectador sen barreiras sociais nin xeracionais ${ }^{5}$.

No aspecto formal, os sinais de identidade do filme explicítanse na súa propia "imperfección": a imaxe queimada polo paso do tempo, as decoloracións, as condicións lumínicas precarias propias da cámara doméstica. Todo queda nun segundo plano; o fundamental é que o Haia consegue rexistrar a súa epopeia nun exercicio de metacinema de grande autenticidade. Así, a catro mans, vaise construíndo un relato no que a xente e a paisaxe cobran vida para amosar a profunda relación entre o home e o mar, na súa intención de poñer en valor a épica dos grandes oficios.

O corazón de Vikingland é a cea de Nadal, unha peza que semella construída na tradición do kammerspiel ${ }^{6}$. Nun diminuto comedor, catro mariñeiros comparten unha modesta comida e a morriña por atoparse afastados do fogar. Rúa, un dos presentes, intúe na videocámara do Haia o medio de rexistro perfecto "para que a nosa xente mire a vida que pasa un mariñeiro". Logo duns minutos onde (por iso de saberse observados) domina a impostura, os homes comezan a esquecerse da cámara; e de xeito progresivo vai xurdindo na escena a "ilusión perfecta", ese efecto que Stendhal (Tubau 2011: 87) consideraba un fito dramático no cal os personaxes parecen escapar a todos os mecanismos de control narrativo para acadar vida de seu.

A cea de Nadal convértese nunha velada presidida polo escepticismo e realza a dimensión existencial dun filme xa en por si inzado de silencios elocuentes, de tantos xestos de loita como de capitulación diante dun destino incerto. Como pano de fondo, a soidade que azouta o ser humano e que nos leva á deriva como os anacos de xeo sobre os que esvara o transbordador no tramo final do filme.

A cea convértese nun ritual, nunha cerimonia que devén en exorcismo comunitario; alí están os catro mariñeiros -o Haia, Manolo, Rúa e o Charli-, pero tamén os ausentes, as sombras das viúvas dos vivos e das súas familias. A odisea de Vikingland é outro gran poema sobre o mar, un fundido en branco sobre a memoria dos nosos.

\section{CONCLUSIÓNS}

O audiovisual galego, como outras disciplinas artísticas, tratou -e trata- con sensibilidade, o drama da emigración. Pero debido ao escaso desenvolvemento do noso cinema o espectador só puido contar polo momento cun número reducido de filmes susceptibles de provocar debate ou reflexión.

Os tres filmes analizados neste artigo ofrecen unha visión panorámica de como se reflectiu a emigración nas nosas pantallas. Dous traballos máis convencionais como Mamasunción, que conta unha sinxela historia de ficción desde o punto de vista dunha anciá que ansía o regreso do seu fillo, e Avión el pueblo ausente, un documental que recolle o testemuño dos que marcharon e dos que decidiron ou non

${ }^{5}$ Vikingland percorreu máis de trinta festivais, estivo presente entre outros nos seguintes: FIDMarsella, Jihlava, Mar del Plata, FICXixón, FICUNAM, Bradford Flaherty Film Seminar, Lima Independiente ou Festival de Cine Radikal de La Paz.

${ }^{6}$ Tipo de representación teatral creada por Max Reinhardt, realizada ante un grupo reducido de espectadores, no cal se busca unha maior proximidade co espectador. 
tiveron máis remedio que quedar. Por outra banda Vikingland, unha película que constrúe o relato da emigración desde dentro, de primeira man, a modo dun diario filmado.

Estes filmes mostran a emigración con crueza. Son traballos necesarios para comprender parte do noso legado como pobo, obras que suscitaron a curiosidade entre a crítica pero tamén en sectores amplos do público. Isto referenda a pertinencia de contar historias que falen sobre a nosa situación social e a condición moral.

\section{REFERENCIAS BIBLIOGRÁFICAS}

ACUÑa PÉREz, Xoán (1999): Chano Piñeiro: unha historia do cinema galego. Vigo: Edicións do Cumio.

Bergner, Verónica, Sebastián Rosal e Geraldine Salles Kobilanski (2013): Entrevista a Xurxo Chirro (dispoñible en: http://www.marienbad.com.ar/entrevista/xurxo-chirro).

Bertrand, Jean René (2000): “La emigración gallega, ¿sistema original?”, Sémata. Ciencias sociais e humanidades 11, pp. 439-455 (dispoñible en: https://dspace.usc.es/bitstream/ 10347/4673/1/pg_443-459_semata11.pdf).

Castro, Rosalía de (2004): Poesía galega completa II (ed. A. Pociña e A. López). Barcelona: Sotelo Blanco.

Chirro, Xurxo (páxina web persoal): www.xurxochirro.com.

Díaz Castro, Xosé María (2014): Nimbos. Vigo: Galaxia.

Fernández, Marcelino e Ramón Villares (1996): Historia da emigración galega a América. Santiago de Compostela: Xunta de Galicia.

FernándeZ, Miguel Anxo (2013): "Unha fermosa carta dentro dunha lata" (dispoñible en: http:// blogdemiguelanxofernandez.blogspot.com.es/2013/03/facendo-memoria-chano.html).

GonZÁLEZ, Helena (2012): "La ausencia y la espera de la mujer sola como afirmación en Rosalía de Castro y Xohana Torres", en J. L. Arráez Llobregat e A. Peral Crespo (eds.), Del instante a la eternidad. Exégesis sobre "la espera" en la escritura de mujeres. Alicante: Universidad, pp. 93-111.

Hervera, María e Marcos Hervera (2011): Avión, el pueblo ausente (documental) (dispoñible en: http://www.rtve.es/alacarta/videos/el-documental/documental-2-avion-pueblo-ausente/2682256/).

PiÑEIRo, Chano (2003): Mamasunción. Santiago de Compostela: Galicia Hoxe. (2006): Sempre Xonxa. A Coruña: IB Cinema.

Sendón, Manuel e Xosé Luis Suárez Canal (1998): Virxilio Vieitez. Álbum. Vigo: Centro de Estudos Fotográficos.

Tubau, Daniel (2011): El guión del siglo 21: El futuro de la narrativa en el mundo digital. Barcelona: Alba.

VÁzQuez González, Alexandre (s. d.): As migracións masivas de galegos a América. Santiago de Compostela: Consello da Cultura Galega, Arquivo da Emigración Galega (dispoñible en: http://www.culturagalega.org/albumdaemigracion/docs/migracions_masivas.pdf).

WaJCMAN, Gerard (2001): El objeto del siglo. Buenos Aires: Amorrortu. 